\title{
O "GAUCHO", O TANGO, PRIMITIVISMO E PODER NA FORMAÇÃO DA IDENTIDADE NACIONAL ARGENTINA
}

Eduardo P. Archetti

Em uma crônica de jornal publicada em 1932, Roberto Arlt, um dos maiores escritores modernistas da Argentina, protestava contra o vasto uso da imagem do gaucho em tudo que pudesse ser definido como argentino. A imagem era aplicada a coisas tão diversas como jogadores de pólo com nomes como Miles, Lacey, Harrington ou N elson; orquestras de tango com músicos chamados Cattaruzzo, Nijisky, Dupont ou M üller; cantores de tango cujas canções nada tinham a ver com o cenário rural; e jogadores de futebol que exibiam a "coragem criolla", o "entusiasmo gaucho" ou a "típica técnica do Pampa". Em sua queixa, Arlt confirmava a predominância da "imagética gaucha/mestiza" em um modelo de transformação e hibridação que permitiu "crioulizar" e converter simbolicamente em gauchos milhões de imigrantes recebidos pela Argentina desde os anos 1880 (A rlt 1994:101-104). Os gauchos estavam ligados ao passado, à vida rural e, de uma maneira concreta, às raízes culturais. O futebol e o pólo eram práticas esportivas globais importadas. $O$ tango, uma criação recente. Portanto, as atividades de lazer, de dança e esportivas que se haviam tornado populares eram, de certa forma, invenções modernas radicais, modelos de uma transformação e, ao mesmo tempo, de uma continuidade cultural. O modernismo abraçara o romantismo e a tradição. Como já observou Strathern, a noção de “'tradição' é semelhante, mas não exatamente idêntica, à idéia de 'continuidade' e, portanto, a ela se sobrepõe; trata-se da continuidade considerada a partir do ponto de vista daquilo que é tomado como característico ou típico de algo" (1992:14). A tradição e o primitivismo, como veremos mais adiante, são efetivos por serem definidos e percebidos como mecanismos culturais para a regulação da vida social. Conseqüentemente, a tradição pode tanto anteceder quanto ser provocada pelas mudanças. Em outras palavras, a análise da tradição possibilita que se entenda melhor a inovação cultural. Nesse sentido, algumas ideologias nacionalistas - um fenômeno moderno - tendem a 
ser formuladas e articuladas em uma relação íntima com o que é visto como tradicional, como produto de um passado rural idealizado. Alonso (1996) chamou essa ambígua relação latino-americana com o projeto modernizador de "fardo da modernidade".

De 1900 a 1930, a Argentina transformou-se sob o impacto de uma imigração européia maciça, que remodel ou a identidade nacional. O processo de construção do Estado-nação argentino dizia respeito não só à extensão efetiva da autoridade sobre um território e um povo, mas também à constituição de sujeitos como seres "nacionais", aceitando e identificando-se com as demandas que o Estado Ihes viesse a impor. Se a construção do Estado depende, como é largamente reconhecido, de anexar, subjugar e cooptar, a "nação" é seu complemento, devido à sua capacidade de agrupar, gerar compromisso subjetivo e criar um sentimento de pertencimento (ver Bertoni 2001). Um projeto de nação, portanto, mascara sua heterogeneidade e nega espaço tanto às comunidades que nele submergem quanto aos imaginários alternativos que exibe.

Este artigo ilustra esses processos particulares sob o prisma do impacto da imagética e da vestimenta gauchas no tango. Em tal contexto, veremos que as tradições populares e o vestuário gaucho foram elementos-chave de um renascimento nacionalista (ver Goddard 2000). Tentarei mostrar que a conexão entre a vestimenta e a imagética gauchas, em tese pertencentes ao passado, também envolveu o tango - dança e música modernas criadas na Argentina nos anos 1880 e 1890 e exportadas para o mundo no começo do século XX. Examinarei aqui também a confluência do nacionalismo na Argentina com as idéias européias de exotismo na definição de um contexto em que se podia fazer referência ao tango como dança e música gauchas. Nesse período em que as elites argentinas procuravam símbolos nacionais, as relações acidentais e sinuosas entre o tango - produto urbano - e as roupas gauchas ofereceram uma poderosa solução temporária. Não foi por acaso que os europeus, particularmente os parisienses, viram o tango como "dança e música gauchas". Recorrerei à idéia de que, por meio desse deslocamento, as representações que aparentemente estão fora de época e de lugar são reforçadas e "naturalizadas". O poder simbólico repousa, assim, no processo que serve para firmar uma imagética gaucha, obscurecendo, ao mesmo tempo, as ambigüidades que o sustentam (ver M elhuus e Stølen 1996). 


\section{O declínio social do "gaucho" e da literatura gauchesca: a questão de uma linguagem e de uma identidade nacionais}

Desde o fim do oitocentos e ao longo das primeiras décadas do século XX, a A rgentina integrava-se ao cenário global de trocas mercantis maciças, vastas migrações internacionais, rápida urbanização, novas formas de consumo urbano, competições esportivas mundiais e circulação de produtos de cultura de massa. O principal impulso era estrangeiro: trabalho estrangeiro, capital estrangeiro e mercados estrangeiros favoráveis a seus produtos de exportação (carne e cereais). Investidores britânicos detinham cerca de $80 \%$ do sistema ferroviário argentino, grandes extensões de terras no país, a maioria das linhas de bonde e das empresas urbanas de serviço público, e algumas das mais importantes fábricas e indústrias de enlatados. A té a Primeira Guerra M undial, país al gum no mundo exportava mais bens por habitante que a Argentina. A renda per capita era comparável às da Alemanha, Holanda e Bélgica, e mais alta do que as da Espanha, Itália e Suécia (Rock 1993).

Entre 1890 e 1914, a Argentina tornou-se uma das grandes nações de imigrantes do mundo moderno. Em 1914, cerca de um terço de seus quase oito milhões de habitantes - número que o terceiro censo mostrara ser mais que o quádruplo do total apurado no primeiro recenseamento, datado de 1869 - havia nascido no exterior, a maioria na Itália (39,4\%) e na Espanha (35,2\%). Os imigrantes russos, principalmente judeus que haviam fugido da perseguição étnica e política no Império Russo, formavam o terceiro maior grupo $(4,1 \%)$. Sírios e libaneses $(2,7 \%)$ também haviam chegado, deixando para trás outro império opressor, o Otomano. Havia ainda imigrantes da França, da A lemanha, da Dinamarca e da Áustria-H ungria (principalmente sérvio-croatas e pessoas originárias da região do Friuli) (Solberg 1970:38). E os britânicos formavam uma minoria poderosa. É importante assinalar, ademais, que pelo menos um quarto da população era constituído de descendentes de imigrantes das duas gerações anteriores.

A Argentina recebeu, entre 1869 e 1930, mais imigrantes em relação à sua população que qualquer outro país moderno. Esse padrão histórico se refletiu no crescimento e no desenvolvimento da capital, Buenos Aires (a cidade do tango). A cidade passou de 180.000 habitantes, em 1869, para 1.576.000, em 1914. Em 1930, sua população era de quase três milhões, um terço dos quais eram imigrantes (Ferrer 1972:146). A proporção de estrangeiros era de 13,8\% em 1869, 24\% em 1895 e 42,7\% em 1914 (Vázquez Rial 1996:24). Por longos períodos da história de Buenos Aires, a po- 
pulação masculina foi largamente majoritária, particularmente entre a população mais jovem, devido à menor imigração feminina (ver Guy 1991). A capital tornou-se uma espécie de babel cultural, onde o inglês era a língua do comércio e da indústria, o francês, a da cultura, e as da vida cotidiana eram uma mistura do espanhol (e do galego), do italiano (vários dialetos) e de outras línguas da Europa do Leste e do Oeste. M uito antes de a antropologia descobrir a cultura global, as diásporas e os encontros multinacionais, a Buenos Aires dos anos 20, como Nova York, representava, de fato, um "espaço verdadeiramente global de conexões e dissoluções culturais" (Clifford 1988:4).

Naquela década, efetivara-se na A rgentina uma transformação social e econômica e consolidara-se uma democracia incipiente. $O$ país havia "sobrevivido" à chegada de milhões de imigrantes e às mudanças provocadas pelas novas tecnologias, pelas conexões globais, pela imersão no mercado mundial e pela urbanização maciça (em 1930, a população urbana equivalia a $63 \%$ do total). A Argentina e a cidade de Buenos Aires não só eram heterogêneas no sentido objetivo - como produtos de misturas étnicas e culturais -, mas também eram imaginadas como tal por intelectuais, escritores, políticos e, é claro, pela população em geral (ver Halperin Donghi 1987; Sarlo 1996; Bernand 1997). Imaginar uma "comunidade nacional imaginada" homogênea nesse quadro histórico não era tarefa fácil, exigindo muito mais esforço do que no caso de sociedades etnicamente mais homogêneas e com transformações demográficas menos dramáticas. Rojas, um dos mais importantes escritores nacionalistas do período, tinha a imigração maciça e a falta de uma política educacional orientada para a integração dos estrangeiros por uma ameaça à reprodução cultural e ao pertencimento nacional (1909:89-90). Imagens como "invasão", "corrupção" da língua e "caos" moral e sexual são evocadas em seus trabalhos e nos de outros escritores como Lugones, Galvez, Bunge e Ibarguren. M esmo Borges, um escritor modernista, se referiu a Buenos Aires, em 1926, como uma fusão cosmopolita, contrastando a margem da cidade e sua população criolla com o centro, onde reinavam o "babélico, o pitoresco, o retirante dos quatro cantos do mundo, o mouro e o judeu" (1993:24).

Na época da Primeira Guerra, os nacionalistas já haviam encontrado no homem gaucho - o vaqueiro livre que caval gava pelos pampas, vivendo da caça e da coleta e trabalhando por um salário apenas quando necessário - um símbolo que representasse a herança cultural da nação sob a "ameaça" da imigração (Solberg 1970; Slatta 1985; Prieto 1988; Delaney 1996). A intelligentsia liberal argentina imaginara que a chegada 
de imigrantes da Europa Central e Setentrional levaria à purificação da raça e ao melhoramento radical da ética de trabalho da população criolla. $O$ resultado não foi exatamente o esperado. Prevaleceram os italianos, os espanhóis, os judeus e os que provinham do Oriente M édio e do Extremo Oriente (Schneider 1996), e os nacionalistas continuaram a reivindicar a figura e o significado cultural do gaucho como o principal tipo simbólico da nacionalidade argentina. De maneira bastante paradoxal, o discurso nacionalista reviveu os temas "bárbaros" que tinham sido condenados a desaparecer por meio da imigração, da hibridação e da modernização. Essa reinvenção da tradição se tornou possível devido ao lugar privilegiado que a literatura gauchesca ocupava no consumo literário popular urbano e rural desde os anos 1880. O poema épico M artín Fierro, escrito por J osé Hernández em 1872, em um estilo que reproduzia a linguagem rural gauchesca, era uma síntese da idealização do gaucho (Borges 1980: 108). A história do gaucho que lutava contra a injustiça do Estado a fim de manter sua liberdade foi transformada em modelo para uma "Iiteratura nacional". O personagem era acompanhado por outras figuras míticas como Santos Vega e J uan M oreira, ambos nobres gauchos, como ele próprio, lutando pelo que consideravam justo, representando a liberdade e a tradição (ver Ludmer 1988; Rama 1996:50-63). Prieto mostrou que a literatura gauchesca também era lida nas cidades, especialmente entre imigrantes europeus, para os quais a colorida iconografia rural era a única expressão de algo nacional, da Argentina local, "dentro da desordem generalizada produzida pela ingestão cosmopolita" (1988:98-99). Essa literatura criou tipos humanos virtuosos em situações de conflito e tensão, introduzidas pela modernização e pelos valores cosmopolitas. Eram personagens valentes e violentos, mas também elegantes e educados, quando tratados decentemente. Eram homens de honra e coragem, simbolizando imagens aristocráticas idealizadas. Eram, ainda, figuras importantes em outras expressões da cultura popular, como a pantomima, o circo e o Carnaval (Chasteen 2000).

A Argentina era um "país novo", com uma história em construção. A tradição, portanto, tinha de ser imaginada e, em muitos sentidos, recuperada do passado. Em um presente turbulento, afetado pelo influxo de estrangeiros e por um rápido e caótico crescimento das cidades, a Buenos Aires cosmopolita não era, na opinião dos escritores nacionalistas, o lugar certo para se procurar novos símbolos de nacionalidade. Esses símbolos foram encontrados no passado, no campo, no solo dos pampas e na reconstrução imaginária de uma cultura rural, na literatura gauchesca, com suas figuras masculinas épicas. Borges observou em 1926: 
“Buenos Aires, apesar dos dois milhões de destinos individuais que a abarrotam, permanecerá deserta e sem voz, até que um símbolo a habite. A província, sim, está povoada: lá estão Santos V ega e o gaucho Cruz e M artín Fierro, possibilidades de deuses. A cidade continua à espera de uma poetização" (1993:126).

Esse movimento não estava confinado apenas à literatura. "Sociedades tradicionalistas", "academias criollas" ou "centros criollos" foram fundados com a missão de recriar os costumes do gaucho, que incluíam a música e a dança. De acordo com Vega, no período de 1898 a 1914, foram estabelecidos, na cidade de Buenos Aires e em suas vizinhanças, centenas de sociedades com nomes relacionados às figuras míticas da literatura gauchesca, como M artín Fierro, Los Perseguidos del J uez, Cruz e Tradición de Santos Vega (1981:13-57)1. A recuperação de danças tradicionais perdidas era um dos principais objetivos dessas associações. J untaram-se a esse esforço as companhias itinerantes de teatro (zarzuelas criollas) e o chamado circo criollo, que encenavam dramas gauchos, incluindo música ao vivo e danças tradicionais como parte das performances. A presentavam-se danças como cielitos, estilos, pericones, media cañas e triunfos. Ademais, a incipiente indústria cinematográfica inspirou-se nas tradições gauchas, produzindo filmes com títulos como Alma Criolla, Tierra Argentina, El Gaucho ou Romance Argentino. Nas gravadoras, os rótulos criollo e nacional foram largamente usados para pessoas ou grupos que cantavam canções populares, tenores que interpretavam óperas clássicas e orquestras de tango que receberam o título de orquestra típica criolla. As duas companhias gravadoras mais importantes eram a Records Creole e a Records N ational. É contra esse pano de fundo cultural e histórico que o tango aparece, como representante do urbano e da cidade de Buenos Aires, sendo, ao mesmo tempo, criollo e nacional. Este artigo argumenta, como foi assinalado na introdução, que a mudança é mais bem compreendida como um processo relacionado às tradições porque a existência de continuidades culturais dadas legitima a inovação. As complexidades da representação do tango estão sutilmente relacionadas ao renascimento das tradições gauchas.

\section{As transformações do tango: de dança e música urbanas à representação "gaucha"}

O tango nasceu nos arrabales (subúrbios) de Buenos Aires nos anos 1880. Borges salientou que se tratava de um típico produto suburbano e que, 
apesar de ainda ser importante nos arrabales, a presença rural não influenciava radicalmente seu desenvolvimento. "O tango não é rural, é porteño", escreveu. "Sua pátria são as esquinas rosadas das ruas dos subúrbios, não o campo; seu ambiente, os bairros pobres; seu símbolo, os salgueiros-chorões, jamais o umbu (a árvore típica que representa os pampas)" (1993:103). Uma das figuras sociais do arrabal era o compadre, personagem masculino com raízes nas áreas rurais, geralmente empregado dos matadouros que lá proliferavam. Collier descreveu-o vividamente, como se segue:

“O livre e nômade mundo gaucho havia mais ou menos desaparecido nos anos 1880, embora o compadre suburbano tenha talvez herdado certos valores gauchos: orgulho, independência, masculinidade ostentosa, propensão para resolver problemas de honra à faca. $M$ ais numerosos que os compadres eram os jovens de origem pobre que procuravam imitá-los e que eram conhecidos como compadritos, valentões de rua bem representados na literatura da época e facilmente identificáveis por seus contemporâneos a partir de seu vestuário padrão: chapéu mole, lenço de seda folgado amarrado no pescoço, faca discretamente embainhada no cinto, botas de salto" (1992:94-95).

O tango era, assim, povoado de compadres e compadritos, em uma época em que os heróis gauchos tinham grande importância na cultura e na literatura populares. Gauchos e compadritos, em uma espécie de combinação pouco usual, tornaram-se, durante esse período, personagens representativos nos desfiles de Carnaval realizados em Buenos Aires (Chasteen 2000).

Em 1890, havia já um novo estilo de dança a dois, chamado baile de corte y quebradas, em uma referência às paradas repentinas e às quebradas que o caracterizavam. Era conhecido ainda como milonga, nome que também designava uma dança rural. Na nova modalidade, os compadritos combinavam a milonga com o estilo e o movimento do candombe, a dança popular dos negros argentinos que viviam em Buenos Aires, caracterizada por quebradas e cortes. A quebrada era uma contorção improvisada, bastante atlética; o corte, uma pausa repentina, uma interrupção dos passos normais da dança. Enquanto no candombe homens e mulheres faziam os movimentos separadamente, no tango as quebradas e os cortes eram executados por parceiros que dançavam juntos. Chasteen afirma corretamente que "o perfil característico da coreografia de tango moderna finalmente emergiu de um encontro entre os movimentos do candombe e a coreografia para casais do repertório dos salões de baile internacio- 
nais" (2000:54). O candombe reduziu-se a uma dança convencional durante a segunda metade do século XIX, ao lado de danças populares como a polca, a mazurca e especialmente a habanera, o ritmo hispano-cubano da moda na América Latina. Carpentier observou que, no tango, a população negra argentina, quase desaparecida no fim do século XIX, foi recuperada em uma espécie de casamento inesperado com a habanera européia mais do que com a contradanza cubana (2001:99). É, portanto, comumente aceito que a influência dos movimentos do candombe na coreografia para casais da habanera é o antecedente mais próximo do tango. Collier resume perfeitamente esse processo criativo:

“O tango [...] foi apenas uma fusão de elementos díspares e convergentes: as contorções bruscas e semi-atléticas do candombe, os passos da mi longa e da mazurca, o ritmo e a melodia adaptados da habanera. Europa, América e África reuniram-se nos arrabales de Buenos Aires, e assim nasceu o tango - por improvisação, por tentativa e erro, e por criatividade popular espontânea" (1992:97).

A vida urbana em Buenos Aires transformou-se rapidamente durante as duas primeiras décadas do século XX. Hotéis luxuosos, restaurantes, bistrôs, centenas de cafés, teatros e uma ópera famosa foram construídos por arquitetos europeus. Tal quadro levou a mudanças no uso das horas de lazer e produziu novos ambientes, exteriores ao mundo da privacidade e do lar. O aparecimento desses espaços criou condições novas para a participação pública e o divertimento, em um ambiente dominado pela vida cultural, pelos esportes e pelas preocupações sexuais. Quatro instituições onde o tango imperava proporcionavam ao público novos estímulos e oportunidades para pôr em cena suas fantasias sexuais: o bordel, a "academia de dança" (academia de baile), o "café com garçonetes" (café de camareras) e os cabarés. Essas arenas davam espaço, ainda que de maneira muito particular, às mulheres. $O$ tango estava diretamente relacionado a esses contextos públicos: como dança, fora originalmente criado nos bordéis e nas "academias de dança", nas duas últimas décadas do oitocentos. Mais tarde, no começo do século XX, o cabaré tornou-se um espaço público privilegiado para a dança e a música. Supõe-se que, originalmente, o tango era apenas um estilo instrumental, dançado principalmente por pares masculinos. No entanto, não se pode ignorar a importância das "academias de dança" como lugares de encontro para homens e "garçonetes" ou para casais. O primeiro período do tango, de 1880 a 1920, foi chamado la Guardia Vieja. Harpa, flauta, violino e violão dominavam 
a orquestra até os anos 20, quando o piano e o bandoneón foram gradualmente introduzidos. Uma vez que o principal objetivo era fazer música para dançar, o estilo de execução era "oral", no sentido de que os músicos improvisavam o tempo todo, sem realizar solos propriamente ditos. A música tomou a forma de uma espécie de diálogo entre a orquestra e os dançarinos - diálogo em que a improvisação musical estava intimamente associada a uma coreografia "erótica" rica e complexa. No começo, então, o tango era para dançar e não para ouvir. Os textos que acompanhavam a música eram diretos, ousados, insolentes e, na opinião de muitos, refletiam uma espécie de exibicionismo masculino primitivo (ver Romano 1991).

Um novo tango desenvolveu-se depois dos anos 20, o tango de la Nueva Guardia (Ferrer 1960:31-36). Tanto a composição musical desse período quanto as novas orquestras davam mais liberdade aos solistas, reduzindo drasticamente o grau de improvisação. Os maestros, por sua vez, passaram a se preocupar mais com detal hes e nuanças na orquestração do que com execuções de solos improvisados. Nesse sentido, o tango evoluiu na direção oposta à do jazz. A mudança mais importante, contudo, pode ser observada nas letras. Os novos autores do tango contavam histórias compactas e comoventes sobre personagens e dilemas morais facilmente entendidos e identificados por um público das classes média e bai$x a$, vasto e heterogêneo. $O$ tango, assim, deixou de ser uma expressão essencialmente instrumental para se tornar principalmente uma narrativa interpretada por uma pletora de cantores - homens ou mulheres - extraordinários.

O tango gradualmente penetrou no teatro popular, o sainete, tomando o lugar das outras músicas e das danças que predominavam no teatro criollo (zarzuelismo criollo). A primeira apresentação foi em 1918, no sainete Los Dientes del Perro, onde Carlos Gardel cantou Mi N oche Triste, composta em 1917 por Pascual Contursi. Na mitologia do tango, essa canção inaugurou a época da Nova Guarda. Desde então, e durante os anos 20 , houve tangos, orquestras e cantores nos mais populares sainetes, normalmente apresentados no contexto dos cabarés, uma arena tipicamente urbana.

As orquestras entraram, também, nos cabarés e nos salões de dança. Os cabarés de Buenos Aires nos anos 20 eram, em geral, elegantes, mas também escuros e reservados. Não se tratava, certamente, de lugares para entretenimento familiar. O cabaré tornou-se tanto uma arena real quanto imaginada para "passar o tempo" e, para muitas mul heres, para "se divertir", mesmo que apenas uma minoria delas de fato ingressasse em sua esfera. Era tanto um espaço físico real quanto um palco dramáti- 
co para muitas das histórias do tango. Nas letras de diversas canções, o cabaré aparece como um lugar-chave para a atração erótica, uma imagem poderosa que contrastava com o lar, o bar local e o barrio (o bairro). Em tal cenário, bem como em outros locais de dança, predominavam as roupas urbanas, modernas, elegantes e sofisticadas. Nem os dançarinos nem os músicos ou os cantores usavam roupas gauchas, cujo lugar evidentemente não era aquele. $\mathrm{O}$ tango desconectou-se, portanto, das origens rurais, dos trajes mistos dos compadritos, e tornou-se uma representação de um estilo de vida por excelência urbano.

A globalização do tango ocorreu durante esse período, com a ajuda da tecnologia moderna: o rádio, os filmes e os discos. Alguns cantores (como Carlos Gardel) e orquestras se tornaram famosos mundo afora. Esse mesmo processo de globalização serviu para inventar uma "tradição", um espel ho no qual os argentinos podiam se ver, precisamente porque ali os "outros" começaram a vê-los. A narrativa, a dança e a música, que formavam as diferentes faces do tango, tornaram-se um elemento-chave na criação de um produto cultural argentino "típico". Os textos, como discurso escrito, converteram-se em uma espécie de "poética popular". Sem o poder da música, no entanto, o impacto das palavras provavelmente teria sido bastante diferente. A poderosa combinação de texto e música dava às histórias emocionais escritas uma dimensão especial, porque fazia delas objeto de canto e dança. Na Europa, por sua vez, a música e a dança eram mais importantes que as letras. Nesse contexto, e especialmente quando as orquestras ou os dançarinos se apresentavam em cabarés e em diferentes tipos de show, as roupas gauchas, como símbolo da Argentina típica, ganhavam importância.

O tango, como dança, chegou a Paris logo nos anos 10 e era considerado tão exótico quanto gêneros musicais como a música tropical cubana, o flamenco, as danças russas e as havaianas e, mais tarde, o jazz norteamericano ${ }^{2}$. É nesse contexto que uma dança urbana será associada a uma corporalidade tipicamente gaucha. O ol har europeu condicionou a evolução da dança e o modo como se apresentava a oposição entre um erotismo selvagem e um sofisticado. O vestuário era importante no estabelecimento das fronteiras simbólicas e, na França de 1913, podia-se dizer que praticamente tudo estava relacionado ao tango: chás dançantes, champanhe, chocolate, jantares, exposições, tudo ao som de tango (Zalko 1998:72). A cor-tango, um laranja intenso, era popular na confecção de roupas femininas. Tango era ainda o nome de uma bebida de sucesso, a mistura de cerveja e granadina (xarope de romã), que até hoje é possível se conseguir em Paris. $O$ impacto no vestuário feminino também foi importante: os ves- 
tidos de coquetel tipo tango, saias-calças harém e o espartilho tango foram as inovações mais bem-sucedidas. $O$ último foi considerado revolucionário porque era flexível e levou muitas mulheres a abandonar os espartilhos rígidos mais ortodoxos (Savigliano 1995:125).

O tango era uma experiência diferente não apenas por ter trazido as mudanças que mencionei, mas também por ter saído de um lugar distante, de um país com um vasto pampa povoado por gauchos, uma terra que atraíra, nas décadas anteriores, milhões de imigrantes europeus. Savigliano afirma que o fascínio do tango como dança não estava necessariamente relacionado a uma sensualidade instintiva, como no caso de muitas danças "primitivas", mas ao que ela chama de processo de sedução: um casal dançando e mantendo seus impulsos eróticos sob controle, "em uma mútua medição de forças" (1995:110). No entanto, o tango era visto como uma dança exótica, vinda de um lugar com uma atmosfera de primitivismo. André de Fouquières, um pedagogo de dança, afirmou em 1913 que o tango

“[...] era uma dança dos famosos gauchos, os vaqueiros da A mérica do Sul, homens rudes que evidentemente não podem apreciar as maneiras delicadas de nossos salões - seu comportamento vai de uma corte brutal a um corpo-a-corpo que parece uma luta. $\mathrm{O}$ tango [...] não pode ser diretamente importado. Tem de ser parado na alfândega para uma séria inspeção e deveria ser submetido a sérias modificações" (1913:58).

O primitivismo era a imposição de um conjunto de expectativas européias aos outros e a seus produtos culturais, como assinala Connelly (1999). Era visto como algo que "subvertia as fundações da ordem racional a fim de buscar o irracional por si só" (Connelly 1999:14). Como expressão artística, era considerado rude, ingênuo, veículo de grande sentimento e grande paixão, carecendo de narrativa estruturada e dando forte ênfase a exibições corporais extremas. Nesse sentido, o tango era tão "primitivo" quanto a arte africana primitiva. A paixão parisiense do pós-guerra por l'art nègre criou um intenso culto de figuras e máscaras exóticas da arte africana que se ajustava ao interesse europeu pela estética cubista e surrealista. Assim, a associação com a vida selvagem dos gauchos nos pampas argentinos não era um acidente, era central para a arte visual moderna. Nos anos 10, dançarinos argentinos tinham problemas para encontrar emprego em Paris e muitos, quando conseguiam, tinham de usar roupas gauchas. Estava-se querendo dizer, dessa forma, que eram argentinos autênticos os que apresentavam aquela dança "selvagem" e "exótica". O 
mesmo ocorreu com orquestras e dançarinos em excursão em toda a Europa e nos Estados Unidos. Nochlin caracterizou essa atitude como uma maneira de definir o "outro" em relação a uma "singular e inapreensível vida selvagem" (1989:50).

No entanto, a fascinação pelo primitivismo nas representações européias sobre o tango era algo ambivalente, visto que ele veio a tornar-se uma dança de salão típica. A coreografia exótica, selvagem e original, desenvolvida por dançarinos argentinos, foi transformada por pedagogos franceses em uma dança estilizada, quase um balé. Concomitantemente a essa inserção no mercado de trabalho, a "coreografia moderna" tornou-se um campo dominado pelos pedagogos de dança franceses. Concretamente, De Fouquières propôs uma espécie de revolução coreográfica, substituindo os incontáveis passos por apenas seis figuras principais. Savigliano observa que "essas tentativas de domesticar o tango foram, na maioria, bem recebidas" (1995:122). O tango foi então transformado em uma dança globalizada, uma vez que se produziu uma gramática coreográfica reduzida. Borges comentou essa transformação, assinalando que, antes do triunfo em Paris, o tango era uma "orgiástica diabrura" e, depois, apenas "uma maneira de andar" (1980:89) - de selvageria sexual, converteu-se em dança urbana.

Bioy Casares observou que o tango que Rodolfo Valentino e Beatrice Domingues, ambos vestindo roupas gauchas, dançavam em The Four Horseman of the A pocalypse, um filme mudo de Hollywood feito em 1921, estabeleceu uma espécie de modelo estético dominante identificado com a Argentina tradicional (1970:27). O escritor concluiu que, em certa medida, a vestimenta gaucha era imposta por uma espécie de olhar colonial. Ainda segundo Bioy Casares, para muitos porteños essa imagem era "falsa", e eles tinham medo de que, no mundo real, as roupas e as atitudes de $V$ alentino fossem identificadas com os gauchos argentinos. A conexão entre a A rgentina, os gauchos, o primitivismo e o tango foi mantida por um longo tempo. M esmo nos anos 30, como o grande poeta do tango Enrique Santis Discépolo constatou, era possível encontrar em Paris orquestras e dançarinos usando roupas gauchas. Discépolo chamou-os de "gauchos incríveis e inexplicáveis" e, no cabaré Le Lapin, chegou a ver um "marinheiro gaucho" (Zalko 1998:138).

Durante os anos 10, na Argentina, estava claro que o tango era o mais típico produto da cultura urbana cosmopolita de Buenos Aires. No interior, o folclore era praticado em áreas rurais e era parte de rituais e cerimônias tradicionais. Destaquei a importância do movimento tradicionalista nas províncias que abrangiam a região do pampa. Na província de 
Santiago del Estero, localizada em uma área relativamente pobre no nordeste da Argentina, Andrés Chazarreta, professor e músico de improviso, iniciou nos anos 10 a compilação de canções populares e a recuperação sistemática de danças tradicionais. Ele reconheceu que sua inspiração nasceu do contato com a literatura gauchesca, do comparecimento a apresentações do circo criollo e da resistência às danças importadas como a mazurca e a polca, ainda presentes em sua província (Vega 1981:102-103). Em 1911, Chazarreta formou uma companhia de dançarinos e músicos e apresentou-se, com grande impacto, em Santiago del Estero ${ }^{3}$. O grupo que dançava chacareras, gatos, escondidos, palitos, huellas, bailecitos e malambos e que vestia roupas gauchas - chamava-se Compañia de Baile Criollo. As visitas a algumas cidades do norte da Argentina e as apresentações naqueles lugares não tiveram o mesmo sucesso. A principal aspiração de Chazarreta, no entanto, era levar seu espetáculo a Buenos Aires. Ele esperou dez anos. Em 1921, com um novo grupo, a Compañia de Arte Nativo, apresentou um show que conquistou o público e a crítica da cidade. Tal foi a resposta que eles se apresentaram, com casa lotada, durante um mês e meio. Vega explica o triunfo do folclore na capital como uma indicação da descoberta pela Buenos Aires "estrangeira e cosmopolita" da existência da "outra Argentina" e de sua população nativa marginalizada, com suas tradições (1981:141-143; ver, também, Alen Lascano 1972). A imprensa definiu unanimemente o sucesso como um exemplo de renascimento nacional.

Também é importante mencionar um forte movimento revival ista iniciado em 1926 na cidade de San Antonio de Areco, na província de Buenos Aires. Ricardo Güiraldes, autor de uma obra-prima da literatura gauchesca, Don Segundo Sombra, foi homenageado por um movimento gaucho. Centenas de pessoas com roupas gauchas e cavalos visitaram-no em sua estância "La Porteña" : tocaram-se e dançaram-se canções populares tradicionais, ouviu-se a "retreta del desierto", organizaram-se corridas de cavalo e o ponto alto da festa foi uma apresentação em que se demonstrava habilidade eqüestre. Formou-se uma comissão local com o objetivo de criar um dia nacional da tradição. Em 1939, o governo da província de Buenos Aires declarou 10 de novembro o Dia da Tradição, em comemoração ao aniversário do escritor J osé Hernández, autor do poema épico gaucho Martín Fierro. Desde aquele ano, a data é celebrada na cidade de San Antonio de Areco (ver Blache 1979).

Exótico e selvagem, o tango foi apropriado pela Europa como símbolo e expressão da Argentina. Sua jornada global dependia, assim, de uma produção cultural particular, que foi generalizada e considerada repre- 
sentante do "nacional". Obviamente, o tango não era a única música nem a única dança da Argentina. O folclore apresentado por Chazarreta, também definido pelos argentinos como nacional, não viajou pelo mundo, continuou rural, local e particular. Paris recriou o tango, enquanto Buenos Aires descobria o interior da Argentina. Neste país, a coexistência do folclore e do tango era evidente. M esmo no período anterior ao início da Nova Guarda, em 1917, grandes cantores dedicaram-se à música criolla das províncias do pampa antes de passar ao tango. A distância entre esses dois gêneros não era tão extrema. Por intermédio do tango, alguns dos artistas se converteram de cantores "rurais" em típicos cantores "urbanos". Ilustrarei essa transformação com exemplos da vida de Carlos Gardel, o mítico cantor de tango argentino.

\section{A transformação de Carlos Gardel: das canções populares tradicionais ao tango}

No começo dos anos 10, Gardel era um cantor de bar de Buenos Aires (do bairro de El A basto) que gozava de certo reconhecimento em outros bairros (Barracas, Corrales e Palermo). Seu repertório era a "música rural criolla" (estilo, cifra, triunfo, cielito, milonga, zamba, vals criollo), canções com grande aceitação em toda a Argentina e também muito populares em Buenos Aires. Em 1912, ele se juntou a Francisco M artino em uma excursão de três meses ao longo da Ferrovia Oeste, cantando em todas as vilas das províncias de Buenos Aires e La Pampa. Em 1913, fez al gumas gravações fonográficas para o selo Columbia. Acompanhando-se ao violão, gravou quinze canções, quatorze das quais foram lançadas, em sete discos com gravação nas duas faces. A maioria delas eram estilos, triunfos e cifras. No mesmo ano, Razzano, um cantor de grande fama, juntou-se a Gardel e M artino. Eles excursionaram pela província de Buenos Aires de juIho a setembro, apresentando-se em clubes sociais, cinemas, bares e, em alguns casos, alojamentos de infantaria. O jornal local de Rojas comentou que "as árias provinciais, os estilos e as vidalitas executados ontem à noite pelo trio [...] foram ouvidos com profundo deleite e falaram diretamente aos corações dos poucos criollos que estavam na apresentação" (uma alusão ao fato de que os imigrantes eram a maioria do público). Os jornais de Bragado informaram que se tratava de uma apresentação de "cantores profissionais" e não de payadores locais. Em General Viamonte, o jornal La Tarde referiu-se a "uma noite encantadora e agradável", proporcionada pelos "três criollos da mais pura estirpe", que "nos deram horas agra- 
dáveis de recordação patriótica, cantando bonitos estilos e várias outras canções com o tradicional sentimento dos gauchos" (Collier 1986:133). A conexão entre a autenticidade criolla e os sentimentos gauchos tradicionais era expressa na música de Gardel, M artino e Razzano. A nação era reproduzida por meio de sua música e de sua dança.

Martino deixou o grupo e nasceu assim o famoso Duo Gardel-Razzano. A estréia formal teve lugar no cabaré Armenonville, em dezembro de 1915, onde el es dividiram a apresentação com uma orquestra de tango integrada por músicos extraordinários como Roberto Firpo no piano, Eduardo Arolas no bandoneón e David Roccatagliata no violino. Como assinalei antes, a cena cultural em Buenos Aires durante os anos 10 era dominada pelas formas tradicionais do teatro argentino: sainete e criollo. Em 1920 , havia cinqüenta teatros na cidade. Os teatros, mas também os cinemas, foram importantes para Gardel e Razzano porque, durante os intermezzos, se oferecia entretenimento ao vivo. O Duo viajou por outras grandes cidades da Argentina: Rosario, Santa Fe e Córdoba. Seu repertório, composto de canções populares criollas - ou melhor, canções populares compostas em idioma tradicional ou do campo - , viria a ser reconhecido como al go original e característico. Em 1916, eles iniciaram também uma carreira internacional, primeiro no Uruguai, depois no Brasil. A viagem a este último país foi muito importante e consolidou a fama dos cantores. Como sempre, eles tocaram nos intermezzos das peças, sainetes ou criollos, interpretadas pela Compañia Dramática Nacional. A imprensa brasileira apresentou a música de Gardel e Razzano como regional, rural e criolla (plangentes canções criollas).

As canções populares estavam agora completamente estabelecidas como parte do repertório de variedades. Gardel e Razzano eram os líderes incontestáveis nesse campo e seu estilo foi largamente imitado por artistas menos talentosos. Um episódio importante foi seu encontro com o famoso ator teatral J osé Alippi. Seu grande sucesso era a encenação do popular drama gaucho J uan M oreira, um dos prediletos dos públicos de Buenos Aires desde a sua primeira apresentação, em 1886. Em novembro de 1915, uma nova e espetacular produção de J uan M oreira foi lançada, com Alippi no papel de Moreira, o gaucho desventurado. Gardel e Razzano cantaram suas canções na cena 6, como parte de uma "grande fiesta rural", contribuindo consideravel mente para o enorme sucesso do espetáculo. Havia música criolla e vestimentas gauchas. A imagética rural era parte de um espetáculo em que se apresentava o estilo de vida gaucho em suas diferentes facetas: o gaucho, suas preferências, sua mulher, seu cavalo, suas danças e as rotinas diárias típicas de sua vida. 
Em 1917-18, Gardel encontrou a nova canção popular, o tango, que era bastante diferente do repertório popular tradicional do Duo. Segundo Collier, "aqueles foram os anos em que Gardel e o tango argentino finalmente se encontraram, os anos em que esse artista magnífico iniciou a ascensão gradual à sua posição incontestável e definitiva como a figura suprema de toda a história do tango" (1986:54). Gardel entrou no mundo do tango e o representou até sua morte repentina, em 1935. M esmo hoje, é visto como a lenda do tango. De 1925 a 1930, consolidou sua fama excursionando pela Europa e se tornando um astro de cinema. No entanto, jamais deixou de cantar canções criollas, introduzindo em seu repertório, em 1925, algumas composições de Chazarreta. Ele as gravou durante os anos 20 e no início dos anos 30. As carreiras de artistas profissionais como Gardel e outros músicos e cantores ilustram as interfaces entre diferentes gêneros de música. O panorama musical da Argentina era variado e refletia as complexidades de uma nação em construção. A distância, portanto, entre as representações gauchas e a modernidade não era tão grande. Nesse contexto, é mais fácil entender por que músicos e cantores de tango aceitaram sem resistência o olhar europeu que os definia como "gauchos".

\section{Conclusão}

M inha contribuição mostra a maneira sutil como o vestuário, a dança e a nação eram expressos por meio do tango e do folclore. Pude mostrar que o olhar externo (pós-colonial) que transformou o tango e as roupas gauchas em representantes da nação foi importante, mas, ao mesmo tempo, que essa conexão estava latente na Argentina e que a transição das canções populares criollas para o tango se deu, em muitos casos, sem conflitos e contradições. A vida de Carlos Gardel é um exemplo da transformação da canção folclórica/vestimenta gaucha no complexo do tango. Ao longo do tempo, as roupas gauchas se tornariam menos identificadas com o tango do que com as canções tradicionais e os movimentos tradicionalistas. O fim da história é claro: o tango tornou-se uma dança mais universal e, nesse processo, as roupas gauchas perderam seu significado. No entanto, o renascimento das canções populares nos anos 40 e 50 consolidou o vestuário gaucho como símbolo de uma nação viril e masculina. O tango, como música e dança, tornou-se, em muitos sentidos, universal e menos nacional, enquanto as canções criollas passaram a representar "a nação profunda". 
Em um país de imigração maciça podemos ver o discurso nacional, as imagens e as apresentações como exemplos de identidades deslocadas, e podemos esperar que se encontre igualmente deslocado o sentido de "alteridade". Em sociedades mais homogêneas, se é que existem, suponho haver um deslocamento menos aparente e acredito que a falta de um modelo explícito de transformação seja mais óbvia: a nacionalidade é definida e vivenciada como algo mais evidente, menos problemático. Em uma sociedade como a argentina, uma imagética nacional acabada tentará integrar uma "alteridade" diferente, pois precisa de todos os fragmentos, de todas as identidades deslocadas e descombinadas, e se apóia no caráter mutante dos grupos que habitam um dado território. A Argentina entrou na modernidade produzindo uma série de identidades e tendências culturais contraditórias que impediam a integração e a restrição a uma imagética nacional única, tal qual a pretendida pelos nacionalistas e pelos representantes dos movimentos tradicionalistas. M eus exemplos mostram que a identidade cultural argentina era, então, altamente dependente da multiplicidade. O folclore envolvia o tango e vice-versa. Gardel era tanto um cantor popular tradicional quanto a quinta-essência do tango. Confrontada com transformações aceleradas, a tradição, ou melhor, aquilo que se definia como tradição era percebido como uma garantia da continuidade cultural, como forma de gerar um senso de pertencimento.

Recebido em 11 de novembro de 2002

A provado em 12 de novembro de 2002

Tradução de Sérgio Paulo Benevides

Eduardo P. Archetti é professor de antropologia social na University of Oslo, Noruega. Publicou recentemente Masculinities. Football, Polo and the Tango in Argentina (1999) e El Potrero, Ia Pista y el Ring. Las Patrias del Deporte Argentino (2001). Um volume organizado com Noel Dyck (Sport, Dance, and Embodied Identities) será publicado em 2003. 


\section{Notas}

1 Oliven (1996) mostrou como o M ovimento Tradicionalista Gaúcho no Brasil contemporâneo recriou identidades regionais e nacionais. Muitas de suas observações e de suas descobertas empíricas podem ser relacionadas à ideologia e aos objetivos do movimento tradicionalista na Argentina.

2 Brody assinalou que as Grandes Exposições de 1867 e 1878 em Paris prepararam o caminho para o grande impacto da música exótica na Exposição de 1889. A comissão organizadora de 1889 considerava a música uma das principais atrações da exposição. Brody afirma que, "pela primeira vez nessa exibição, havia apresentações de música 'exótica' que eram percebidas como apresentações 'musicais'” (1987:94). Ela conclui afirmando que, em 1889, “muitos europeus mostraram-se prontos para tratar a música como um universal cultural, mesmo que suas origens fossem cambojanas ou sioux" (1987:95).

3 Chazarreta definiu a si próprio como um folklorista. Ele não era membro do grupo então incipiente que introduziu a ciência do folclore na Argentina. Em 1900, devido ao trabalho de Roberto Lehmann Nitsche, o conceito de folclore, como maneira de entender as tradições, foi aceito em círculos intelectuais de Buenos Aires. Ricardo Rojas, o escritor nacionalista, apoiou o trabal ho de Chazarreta e declarou-se engajado nesse movimento de recuperação das tradições perdidas do noroeste da Argentina. Em 1922, fundou a primeira seção de folclore no Instituto de Literatura da Universidade de Buenos Aires (Vega 1981:90). 


\section{Referências bibliográficas}

ALEN LASCANO, Luis. 1972. Andrés Chazarreta y el Folklore. Buenos Aires: Centro Editor de América Latina.

ALONSO, Carlos J. 1996. "The Burden of Modernity". Modern Language Quarterly, 57(2):227-235.

ARLT, Roberto. 1994. Aguafuertes Porteñas: Cultura y Política. Buenos Aires: Losada.

BERNAND, Carmen. 1997. Histoire de Buenos Aires. Paris: Fayard.

BERTONI, Lilia Ana. 2001. Patriotas, Cosmopolitas y Nacionalistas: La Construcción de la $\mathrm{N}$ acionalidad A rgentina a Fines del Siglo XIX. Buenos Aires: Fondo de Cultura Económica.

BIOY CASARES, Adolfo. 1970. Memoria sobre la Pampa y los Gauchos. Buenos Aires: Sur.

BLACHE, M artha. 1979. “Dos Aspectos de la Tradición en San Antonio de Areco". Folklore Americano, 27: 163-194.

BORGES, J orge Luis. 1980. Discusión.In: Prosa Completa (vol. 1). Barcelona: Bruguera. . 1993. El I dioma de los Argentinos. Buenos Aires: Sudamericana.

BRODY, Elaine. 1987. Paris: The Musical Kaleidoscope 1870-1925. New York: George Braziller.

CARPENTIER, Alejo. 2001. Music in Cuba. Minneapolis: University of $\mathrm{M}$ innesota Press.

CHASTEEN, J ohn Charles. 2000. “Black Kings, Blackface Carnical, and Nineteenth-Century Origins of the Tango". In: W. H. Beezley e L. A. CurcioNagy (eds.), Latin American Popular Culture: A Introduction. Wilmington, Del.: SRBooks.
CLIFFORD, James. 1988. The Predicament of Culture. Cambridge, M ass: Harvard University Press.

COLLIER, Simon. 1986. The Life, Music, and Times of Carlos Gardel. Pittsburgh: University of Pittsburgh Press. . 1992. "The Popular Roots of the Argentine Tango". History Workshop, 34:92-100.

CONNELLY, Frances S. 1999. The Sleep of Reason: Primitivism in Modern European Art and Aesthetics. Pennsylvania: The Pennsylvania State University Press.

DELANEY, J eane. 1996. “M aking Sense if Modernity: Changing Attitudes toward the Immigrant and the Gaucho in Turn-of-the-Century A rgentina". Comparative Studies in Society and History, 38(3):434-459.

FERRER, Aldo. 1972. La Economía Argentina. Buenos Aires: Fondo de Cultura Económica.

FERRER, Horacio. 1960. El Tango: Su Historia y Evolución. Buenos Aires: A. Peña Lillo Editor.

FOUQUIĖRES, André de. 1913. “Les Danses N ouvelles: Le Tango". Femina, 284:58-61.

GODDARD, Victoria. 2000. "The Virile Nation: Gender and Ethnicity in the Re-construction of Argentinian Past". Goldsmiths Anthropology Research Papers, 4.

GUY, Donna. 1991. Sex and Danger in Buenos Aires. Prostitution, FamiIy, and Nation in Argentina. Lincoln, Nebr.: University of Nebraska Press.

HALPERIN DONGHI, Tulio. 1987. El Espejo de la Historia. Buenos Aires: Sudamericana.

LUDM ER, J osefina. 1988. El Género Gau- 
chesco: Un Tratado sobre la Patria. Buenos Aires: Editorial Sudamericana.

MELHUUS, Marit e STøLEN, Kristi Anne. 1996. "Introduction". In: M. M elhuus e K. A. Stølen (eds.), Machos, M istresses, Madonnas: Contesting the Power of the Latin A merican Gender Imagery. London: Verso.

NOCHLIN, Linda. 1989. The Politics of Vision. Essays in Nineteenth-Century Art and Society. New York: Harper \& Row.

OLIVEN, Ruben. 1996. Tradition M atters: M odern Gaucho I dentity in Brazil. New York: Columbia University Press.

PRIETO, Adolfo. 1988. El Discurso Criollista en la Formación de la Argentina Moderna. Buenos Aires: Sudamericana.

RAM A, Carlos M. 1996. The Lettered City. Durham: Duke University Press. ROCK, David. 1993. "From the First World War to 1930". In: L. Bethell (ed.), Argentina since Independence. Cambridge: Cambridge University Press.

ROJ AS, Ricardo. 1909. La Restauración Nacionalista. Buenos Aires: Ediciones Centurion.

ROMANO, Eduardo. 1991. Las Letras del Tango: Antología Cronológica 19001980. Rosario: Editorial Fundación Ros.

SARLO, Beatriz. 1996. “M odernidad y Mezcla Cultural". In: H. Vázquez Rial (ed.), Buenos Aires 1880-1930: La Capital de un Imperio I maginario. M adrid: Alianza Editorial.

SAVIGLIANO, Marta. 1995. Tango and the Political Economy of Passion. Boulder, Co.: Westview Press.

SCHNEIDER, Arnd. 1996. "The Two Faces of M odernity, Concepts of the Melting Pot in Argentina". Critique of Anthropology, 16(2):173-198.
SLATTA, Richard. 1985. "The Gaucho in Argentina's Quest for Identity". Canadian Review of Studies in Nationalism, 12(1):23-38.

SOLBERG, Carl. 1970. Immigration and Nationalism: Argentina and Chile, 1890-1914. A ustin: The University of Texas Press.

STRATHERN, M arilyn. 1992. After Nature. English Kinship in the Late Twentieth Century. Cambridge: Cambridge University Press.

VÁZQUEZ RIAL, Héctor. 1996. “Superpoblación y Concentración Urbana en un Pais Desierto". In: H. Vázquez Rial (ed.), Buenos Aires 1880-1930. La Capital de un Imperio Imaginario. M adrid: Alianza Editorial.

VEGA, Carlos. 1981. A puntes para la Historia del Movimiento Tradicionalista A rgentino. Buenos Aires: Instituto Nacional de Musicología.

ZALKO, N ardo. 1998. Un Siècle de Tango Paris-Buenos Aires. Paris: Editions du Félin. 


\section{Resumo}

De 1900 a 1930, a Argentina esteve sob o impacto de uma massiva imigração européia que provocou a reconfiguração da identidade nacional. Todavia, o projeto de nação mascara sua heterogeneidade e nega espaço tanto às comunidades que se viram então submersas quanto aos imaginários alternativos que apresenta. $\mathrm{O}$ artigo ilustra esse processo particular do prisma do impacto da imageria e vestimenta gaucha no tango. Nesse contexto, ver-se-á que as tradições e vestimentas gauchas constituíram elementos-chave de um revivescimento nacionalista. Procura-se mostar que a conexão entre a imageria e a vestimenta gaucha, teoricamente pertencentes ao passado, abarca também o tango, a música e dança modernas criadas na Argentina nos anos 1880 e 1890 e exportadas para o mundo no início do século XX. $O$ artigo também examina a confluência do nacionalismo argentino com idéias européias de exotismo e primitivismo na definição de um contexto no qual o tango podia ser referido como música e dança gauchas.

Palavras-chave Tango, Primitivismo, Identidade Argentina, Vestimenta Gaucha
From 1900 to 1930 Argentina was changed under the impact of massive European immigration provoking a remaking of the national identity. Howev$\mathrm{er}$, the project of a nation masks its heterogenity and denies a space both to the communities that become submerged through it and to the alternative imaginaries that it displays. The article is an illustration of these particular processes through the lens of the impact of gaucho imagery and dress in tango. In this context we will see that the gaucho dress and folk traditions were key components of a nationalist revival. The article tries to show that the connection between gaucho imagery and dress, in theory belonging to the past, embraces also tango, the modern dance and music created in Argentina in the 1880s and 1890s and exported to the world at the beginning of the twentieth century. The paper also examines the confluence of nationalism in Argentina with European ideas of exoticism and primitivism in defining an arena in which tango could be referred as gaucho music and dance. Key words Tango, Primitivism, Argentinian Identity, Gaucho Dress 